\title{
COMPOSIÇÃO BROMATOLÓGICA DE PASTAGENS DE INVERNO SUBMETIDAS A PASTEJO POR OVINOS, OBTIDAS POR FÍSTULAS ESOFÁGICAS ${ }^{1}$
}

\author{
Bromatological Composition of Winter Pastures Submitted to \\ Sheep Grazing, Obtained by Esophageal Fistula
}

\author{
Viviane Cristina Luczyszyn \\ Médica Veterinária, M. Sc., Araucária - PR. e-mail: vivicrisluc@uol.com.br \\ Paulo Rossi Junior \\ Zootecnista, Dr., Prof. da UFPR, Curitiba - PR. e-mail: parossi@ufpr.br
}

\begin{abstract}
Resumo
O objetivo do presente estudo foi avaliar a composição bromatológica de pastagens de aveia mais azevém em três áreas contendo isoladamente, cada uma delas, aveia, azevém e o consórcio de aveia mais azevém. Para a colheita de amostras das pastagens foram utilizados 3 ovinos canulados no esôfago. A lotação das pastagens foi fixa e o pastejo contínuo. As colheitas de extrusa foram obtidas em períodos pré-estabelecidos de $0,2,4,6,8,12,36$ e 72 horas. Nas extrusas colhidas foram determinados teores de proteína bruta, fibra em detergente neutro e fibra em detergente ácido. As frações estudadas apresentaram resultados variados, sendo deste linear e negativa, em função do tempo, para os teores de proteína bruta do consórcio $(\mathrm{P}<0,05)$ até polinomial de sexto grau, para os teores de fibra em detergente neutro da pastagem de aveia.
\end{abstract}

Palavras-chave: Aveia; Azevém; Fibra em detergente ácido; Fibra em detergente neutro; Proteína bruta.

\begin{abstract}
The objective of the present study was to evaluate the bromatological composition of oats pastures and ryegrass in three areas having separately, each one of them, the oats, ryegrass and oats more ryegrass. For the harvest of samples of the pastures three sheep with esophageal fistula were used to collect samples from the pastures. The pasture stocking was fixed and the grazing was continuous. The extrusa collected was done in pre-established periods of $0,2,4,6,8,12,36$ and 72 hours. The collected extrusa was evaluated on their levels of gross protein, neutral detergent fiber and acid detergent fiber. The studied samples presented varied results, from linear and negative, due to time, for the levels of gross protein for the association $(P<0.05)$, up to sixth grade polynomial for the levels of neutral detergent fiber from the oats pasture.
\end{abstract}

Keywords: Acid detergent fiber; Crude protein; Neutral detergent fiber; Oats; Ryegrass.

${ }^{1}$ Parte de Dissertação de Mestrado apresentada no Curso de Pós-Graduação em Ciências Veterinárias, da UFPR. 


\section{INTRODUÇÃO}

Devido à diversidade climática, a produção de forragem apresenta flutuações estacionais. No Brasil, ocorre produção satisfatória de forragem baseada em forrageiras estivais no período de primaveraverão e um período crítico com déficit de forragem em decorrência de períodos frios ou secos durante o outono/inverno, os quais limitam o crescimento das pastagens e, conseqüentemente, o rendimento animal (MORAES; LUSTOSA, 1999).

Desta forma, a Região Sul do Brasil apresenta características favoráveis ao cultivo de plantas forrageiras hibernais, as quais podem sanar a falta de alimento durante o inverno.

Entre as forrageiras cultivadas de inverno, os grandes destaques são a aveia preta (Avena strigosa Schreb) e o azevém (Lolium multiflorum Lam) (MORAES; MARASCHIN; NABINGER, 1995). O azevém destaca-se pela sua facilidade de ressemeadura natural, resistência a doenças, pelo bom potencial de produção de sementes e pela versatilidade em consorciações. A aveia é usada preferencialmente em áreas de integração lavoura-pecuária, pois seu menor ciclo de produção não interfere na época de cultivo de lavouras de verão (LESAMA; MOOJEN, 1999). A consorciação de aveia mais azevém é amplamente utilizada na Região Sul do país, já que a aveia possibilita a antecipação da utilização da pastagem e o azevém prolonga este ciclo (QUADROS; MARASCHIN, 1987).

No Paraná, as gramíneas anuais de inverno produzem, em condições de corte, entre 3 e 6 toneladas de MS/ha por ano. Em situações de adubação adequada e época de semeadura cedo (meados de março), as produções se aproximam de 10 toneladas de MS/ha por ano (MORAES; LUSTOSA, 1999).

Para melhor desempenho animal e conseqüente retorno econômico, faz-se necessário um manejo eficiente e racional da forragem, baseado na avaliação dos parâmetros qualitativos e quantitativos. O conhecimento da dinâmica dessas pastagens ajuda a definir estratégias de manejo, proporcionando uma melhor utilização das espécies cultivadas (ROCHA, 2002).

Para que se obtenham melhores índices produtivos em ovinocultura a pasto, é necessário que se faça o planejamento das pastagens, podendo atender ao fornecimento de nutrientes aos animais (GAZDA, 2004), possibilitando níveis aceitáveis de desempenho. Entretanto, para que isso ocorra com eficiência, é necessário o conhecimento da composição bromatológica desta pastagem.

$\mathrm{Na}$ avaliação da composição bromatológica e do valor nutritivo das plantas forrageiras, o estudo do teor de proteína bruta (PB), das fibras em detergente neutro (FDN) e em detergente ácido (FDA) assume papel muito importante na análise qualitativa das espécies de gramíneas e de leguminosas forrageiras, haja vista que esses parâmetros podem influenciar direta ou indiretamente o consumo de matéria seca pelo animal (VAN SOEST, 1994).

No método de colheita pela disponibilidade total de matéria seca, em que se considera toda a planta, observa-se que as amostras da forragem normalmente não são representativas da dieta ingerida pelos animais (EUCLIDES; MACEDO; OLIVEIRA, 1992; GOES, 2003).

Segundo Moraes (2005), comparando o valor nutritivo de uma pastagem de Brachiaria decumbens colhida pelo método da disponibilidade total e por meio de fístula esofágica, observaram que a colheita de amostras com base na disponibilidade total não representou a dieta selecionada pelo animal, pois superestimou o conteúdo fibroso e subestimou os teores de proteína bruta do pasto.

$\mathrm{O}$ uso de animais fistulados no esôfago permite a colheita de boas amostras da forragem pastejada (EUCLIDES; MACEDO; OLIVEIRA 1992).

Avaliou-se, neste estudo, a composição bromatológica de pastagens anuais de inverno, com colheita de amostras por meio de fistula esofágica em ovinos submetidos a sistema de pastejo contínuo. 


\section{MATERIAL E MÉTODOS}

As pastagens foram implantadas no início do mês de julho de 2001 e constituíram-se de uma área de aveia, uma de azevém e uma de consórcio de aveia mais azevém. Para uma área de 1 ha utilizouse $100 \mathrm{~kg}$ de sementes de aveia preta, para uma área de 1,1 ha utilizou-se $50 \mathrm{~kg}$ de sementes de azevém e para uma área de 1,1 ha de consórcio utilizou-se $60 \mathrm{~kg}$ de sementes de aveia e $35 \mathrm{~kg}$ de sementes de azevém, todas fiscalizadas.

Aos 40 dias de plantio, foi realizada cobertura das áreas com $100 \mathrm{~kg} / \mathrm{ha}$ de nitrogênio na forma de uréia em uma única aplicação e aos 60 dias teve início o período de pastejo.

Os animais utilizados eram mestiços Suffolk, com idade média de 18 meses. Para colheita de extrusa, utilizaram-se três ovinos machos implantados com cânulas esofágicas (com peso médio de $70 \mathrm{~kg}$ ).

Para que a pressão de pastejo fosse mantida, foram utilizados sete borregos (peso médio de 94,6 kg) e 18 borregas (peso médio de $57 \mathrm{~kg}$ ). Os borregos e borregas mantiveram a pressão de pastejo e coletores foram os animais fistulados no esôfago. A pressão de pastejo foi determinada tomando-se por base uma oferta de forragem de $7 \%$ do peso vivo e o pastejo foi contínuo.

A implantação da cânula esofágica foi feita conforme a técnica descrita por Bishop e Froseth (1970), citado por Lima (1998), e teve como objetivo possibilitar a colheita de amostras da dieta.

A disponibilidade (oferta) de forragem foi determinada para cada área experimental (aveia, azevém e aveia mais azevém) pelo método do quadrado (GARDNER, 1986).

O início da colheita da extrusa foi em 09/09/2001 no tratamento azevém, em 10/09/2001 no tratamento aveia e em 11/09/2001 no tratamento aveia mais azevém. As colheitas foram seqüenciais a cada três dias no mesmo tratamento. Os animais passaram nove vezes em cada tratamento e houve o descarte de seis dias de colheita (dois por tratamento). Assim, o total de colheitas foi de sete por tratamento, considerando três tratamentos e três animais coletores, resultando em 63 amostras de extrusa.

Para que o material pudesse ser recolhido, foi adaptada uma bolsa coletora em cada animal, presa por presilhas ao longo do pescoço dele e que tinha, além desta função, a de separar o material da saliva pelo fundo telado.

Após a secagem e trituração das amostras de pastagens selecionadas pelos animais coletores, procedeu-se as análises laboratoriais para determinação da proteína, fibra em detergente neutro e fibra em detergente ácido dos materiais em estudo conforme as técnicas descritas por Pereira e Rossi Júnior (1995).

Os dados de composição bromatológica foram analisados por regressão, correlacionando dias de pastejo com composição das frações estudadas.

\section{RESULTADOS E DISCUSSÃO}

Os dados relativos à composição bromatológica da aveia, azevém e do consórcio estão apresentados na Tabela 1. 
TABELA 1 - Valores da proteína bruta (PB), fibra em detergente neutro (FDN) e fibra em detergente ácido (FDA) das pastagens avaliadas, nos intervalos de colheita

Table 1 - Values of crude protein (PB), neutral detergent fiber (FDN) and acid detergent fiber (FDA) of the evaluated pastures, in the collection intervals

\begin{tabular}{|c|c|c|c|c|}
\hline Pastagem & $\begin{array}{c}\text { Intervalo de } \\
\text { Dias de Colheita }\end{array}$ & Proteina & FDN & FDA \\
\hline \multirow{8}{*}{$\begin{array}{c}\text { Aveia } \\
+ \\
\text { Azevém }\end{array}$} & 0 & 21,23 & 55,85 & 29,88 \\
\hline & 3 & 21,25 & 54,04 & 26,26 \\
\hline & 9 & 19,37 & 54,02 & 33,64 \\
\hline & 12 & 18,21 & 52,86 & 33,89 \\
\hline & 15 & 17,44 & 51,47 & 33,83 \\
\hline & 18 & 17,52 & 50,53 & 33,11 \\
\hline & 21 & 15,68 & 48,38 & 15,62 \\
\hline & Média & 18,67 & 52,45 & 29,66 \\
\hline \multirow{8}{*}{ Azevém } & 0 & 24,82 & 58,59 & 30,51 \\
\hline & 3 & 23,53 & 53,45 & 31,51 \\
\hline & 9 & 21,14 & 53,29 & 27,30 \\
\hline & 12 & 20,69 & 54,31 & 30,34 \\
\hline & 15 & 22,45 & 52,72 & 30,19 \\
\hline & 18 & 16,29 & 48,38 & 27,55 \\
\hline & 21 & 17,79 & 48,87 & 31,68 \\
\hline & Média & 20,95 & 52,80 & 29,87 \\
\hline \multirow{8}{*}{ Aveia } & 0 & 18,79 & 57,60 & 34,75 \\
\hline & 3 & 20,27 & 57,42 & 33,84 \\
\hline & 9 & 17,74 & 63,02 & 43,39 \\
\hline & 12 & 14,14 & 56,57 & 30,79 \\
\hline & 15 & 14,58 & 62,22 & 46,25 \\
\hline & 18 & 16,98 & 53,84 & 38,89 \\
\hline & 21 & 14,82 & 57,36 & 39,51 \\
\hline & Média & 16,76 & 58,29 & 38,20 \\
\hline
\end{tabular}

O tratamento azevém apresentou valores médios de 20,95\% para $\mathrm{PB}$, o que estaria bastante inferior ao valor de 31,65\% para o início do ciclo, porém, acima do valor encontrado no final do ciclo vegetativo $12,2 \%$ (ROSO, 1999).

O tratamento aveia apresentou composição bromatológica semelhante aos valores encontrados por Reis (1983), de 14,5\% PB e 30,1\% FDN e por López e Mühlbach (1991), de 11,29\% PB e 31,51\% FDN, porém apresentando valores um pouco mais elevados para o FDN. É preciso salientar que na área de aveia iniciou-se o pastejo próximo ao final do seu ciclo vegetativo e além do pouco desenvolvimento apresentado pela forragem, o seu desempenho ficou prejudicado também pelo ataque de pragas e invasoras.

Os valores médios encontrados 18,67\% para PB para o consórcio aveia mais azevém estão um pouco superiores aos valores encontrados por Lupatini (1998), cujo valor médio foi de 16,42\%, porém semelhante ao valor de 18,1\% encontrado por Roso (1999) e de 18,12\% encontrado por Restle, Roso e Soares (1999).

A relação existente entre $\mathrm{PB}$ e dias de pastejo, no tratamento aveia mais azevém, foi negativa (efeito linear, $\mathrm{P}<0,05)$, em função da perda natural da qualidade das forragens ao longo do ciclo (TABELA 2). O FDN não apresentou uma tendência clara (efeito polinomial de grau 6$)(\mathrm{P}<0,05)$. Essas 
variações podem estar relacionadas ao fato de que as amostras (extrusas) foram obtidas por seleção (preferência) dos animais coletores.

O fato de os animais retornarem às áreas a cada terceiro dia pode ter levado a uma variação na composição botânica da pastagem, que não permitiu um perfeito acompanhamento da composição bromatológica ao longo do tempo. O FDA apresentou efeito quadrático ( $<<0,05)$ (TABELA 2).

Valores de FDA e FDN deveriam ter acompanhado uma mesma tendência, porém em sentidos opostos, isto é, uma elevação no teor de FDN deveria resultar em uma redução nos valores de FDA, porém isso não foi observado no presente trabalho.

Os valores da PB e FDN, do tratamento azevém, apresentaram efeito linear $(\mathrm{P}<0,05)$ (TABELA 2). Os valores de FDN não se elevaram ao longo do tempo, com o decréscimo do teor de PB, mas também declinaram de 58,59\% no dia zero, até 48,38\% no $18^{\circ}$ dia (TABELA 1). Logo, a perda de qualidade da pastagem de azevém, caracterizada pela redução no teor de proteína, não resultou em valores mais elevados de FDN, como era esperado ao longo do ciclo de crescimento. O FDA apresentou efeito polinomial de quarto grau $(\mathrm{P}<0,05)$ (TABELA 2). Houve grande variação na composição bromatológica ao longo dos dias de colheita, que pode ter ocorrido em função da seletividade dos animais coletores, cada vez que retornavam à área.

TABELA 2 - Equações de regressão para valores da proteína bruta (PB), fibra em detergente neutro (FDN) e fibra em detergente ácido (FDA) em função dos dias de colheita, de pastagens de aveia mais azevém (AV+AZ), azevém (AZ) e aveia (AV)

Table 2 - Regression equations for values of the crude protein (CP), neutral detergent fiber (NDF) and acid detergent fiber (ADF), in function of the days of collection, pastures of oats + ryegrass $(A V+A Z)$, ryegrass $(A Z)$ and oats $(A V)$

\begin{tabular}{|c|c|c|c|c|}
\hline \multicolumn{2}{|c|}{ Tratamento } & Equação & $\mathrm{CV}(\%)$ & $\mathrm{R}^{2}$ \\
\hline \multirow{3}{*}{$A V+A Z$} & PB & $y=21,5398-0,2577 x$ & 6,15 & 0,9599 \\
\hline & FDN & $\begin{aligned} y= & 55,8500-1,3308 x+0,3177 x^{2}-0,0259 x^{3}+9 E(-0,5) x^{4}- \\
& 6 E(-0,5) x^{5}-2 E(0,6) x^{6}\end{aligned}$ & 6,37 & 1,0000 \\
\hline & FDA & $y=26,0801+1,9754 x-0,1063 x^{2}$ & 5,46 & 0,9493 \\
\hline \multirow{4}{*}{$\mathrm{AZ}$} & PB & $y=24,7585-0,3514 x$ & 8,34 & 0,7543 \\
\hline & FDN & $y=56,4976-0,2271 x$ & 9,24 & 0,7613 \\
\hline & FDA & $y=30,2870-1,4151 x-0,6927 x^{2}-0,0713 x^{3}-0,0019 x^{4}$ & 9,62 & 0,9926 \\
\hline & $\mathrm{PB}$ & $y=19,0997-0,2189 x$ & 7,61 & 0,5703 \\
\hline \multirow[t]{2}{*}{ AV } & FDN & $\begin{aligned} y= & 57,5970-26,3490 x+16,0830 x^{2}-3,1873 x^{3}+0,2822 x^{4}- \\
& 0,0116 x^{5}+0,0002 x^{6}\end{aligned}$ & 5,26 & 1,0000 \\
\hline & FDA & $y=33,6866+0,2064 x$ & 6,38 & 0,1733 \\
\hline
\end{tabular}

$\mathrm{CV}=$ coeficiente de variação 
A PB no tratamento aveia apresentou efeito linear $(\mathrm{P}<0,05)$, sendo que os teores de PB variaram de 20,27\% a 14,14\% (TABELA 1). O FDN apresentou efeito polinomial de sexto grau $(\mathrm{P}<0,05)$ (Tabela 2), os teores de FDN variaram entre 63,02\% a 53,84\% (TABELA 1). O FDA apresentou efeito linear $(\mathrm{P}<0,05)$ (TABELA 2), onde os teores de FDA variaram entre 30,79\% a 46,25\% (TABELA 1).

\section{CONCLUSÕES}

A variação na composição bromatológica da extrusa colhidas pelos animais, ao longo dos dias de colheita, demonstra que os animais selecionaram o material que ingeriram, toda vez que retornavam para um pastejo a cada terceiro dia.

Desta forma, o presente trabalho propõe que, para uma melhor avaliação da composição bromatológica de extrusas obtidas por cânula esofágica, das pastagens estudadas, é necessário: maior período de coleta (mínimo de 90 dias); permanência dos animais coletores em cada tratamento, durante todo o período de coleta e maior número de animais coletores.

\section{REFERÊNCIAS}

EUCLIDES, V. P. B.; MACEDO, M. C. M.; OLIVEIRA, M. P. Avaliação de diferentes métodos para se estimar o valor nutritivo de forragens sob pastejo. Revista Brasileira de Zootecnia, v. 21, n. 4, p. 691-702, 1992.

GARDNER, A. L. Técnicas de pesquisa em pastagens e aplicabilidade de resultados em sistemas de reprodução. Brasília: IICA / EMBRAPA - CNPGL, 1986. 197 p.

GAZDA, T. L. Produção de ovinos submetidos a duas alturas diferentes de pastejo em aruana (Panicum maximum jacq. Cv. Aruana). In: GRASSLAND ECOPHYSIOLOGY AND GRAZING ECOLOGY, 2. 2004, Curitiba. Anais eletrônico... Curitiba: UFPR, 2004. 1 CD-ROM.

GOES, R. H. T. B. Avaliação da pastagem de capim Tanner-Grass (Brachiaria arrecta), por três diferentes métodos de amostragem. Revista Brasileira de Zootecnia, v. 32, n. 1, p. 64-69, 2003.

LESAMA, M. F; MOOJEN, E. L. Produção animal em gramíneas de estação fria com fertilização nitrogenada ou associadas com leguminosa, com ou sem fertilização nitrogenada. Ciência Rural, v. 29, n. 1, p. 123-128, 1999.

LIMA, J. A. Seletividade por bovinos em pastagem natural. 2. valor nutritivo. Revista Brasileira de Zootecnia, v. 27, n. 3, p. 444-452, 1998.

LÓPEZ, S. E.; MÜHLBACH, P. R. F. Efeito de diferentes tratamentos na composição químicobromatológica da aveia branca (Avena sativa L.) conservada nas formas de silagem ou feno. Revista Brasileira de Zootecnia, v. 20, n. 4, p. 333-338, 1991.

LUPATINI, G. C. Avaliação da mistura de aveia preta e azevém sob pastejo submetida a níveis de nitrogênio. Pesquisa Agropecuária Brasileira, v. 33, n. 11, p. 1939-1943, 1998.

MORAES, A.; MARASCHIN, G. E.; NABINGER, C. Pastagem nos ecossistemas de clima subtropical: Pesquisas para o desenvolvimento sustentável. In: SIMPÓSIO SOBRE PASTAGEM NOS ECOSSISTEMAS BRASILEIROS, 1995, Brasília. Anais... Brasília: Sociedade Brasileira de Zootecnia, 1995. p. 147-200.

MORAES, A.; LUSTOSA, S. B. C. Forrageiras de inverno como alternativas na alimentação animal em períodos críticos. In: PEIXOTO, A. M. Alimentação suplementar. Piracicaba: FEALQ, 1999. p. $147-166$.

Rev. Acad., Curitiba, v. 5, n. 4, p. 345-351, out./dez. 2007 
MORAES, E. H. B. K. Avaliação qualitativa da pastagem diferida de Brachiaria decumbens stapf., sob pastejo, no período da seca, por intermédio de três métodos de amostragem. Revista Brasileira de Zootecnia, v. 34, n. 1, p. 30-35, 2005.

PEREIRA, J. R. A.; ROSSI JÚNIOR, P. Manual prático de avaliação nutricional de alimentos. Piracicaba: FEALQ, 1995. 25 p.

QUADROS, L. F. F.; MARASCHIN, G. E. Desempenho animal em misturas de espécies de estação fria. Pesquisa Agropecuária Brasileira, v. 22, n. 5, p. 535-541, 1987.

REIS, R. A. Produção e qualidade da forragem de aveia (Avena spp). Revista Brasileira de Zootecnia, v. 22, n. 1, p. 99-109, 1993.

RESTLE, J.; ROSO, C.; SOARES, A. B. Produção animal e retorno econômico em misturas de gramíneas anuais de estação fria. Revista Brasileira de Zootecnia, v. 28, n. 2, p. 235-243, 1999.

ROCHA, M. G. Perdas de forragem em gramíneas anuais sob doses de nitrogênio. In: REUNIÓN DE GRUPO TECNICO EN FORRAJERAS DEL CONO SUR, 19., 2002, Mercedes. Anais... Mercedes: INTA, 2002. p. 105.

ROSO, C. Produção e qualidade de forragem da mistura de gramíneas anuais de estação fria sob pastejo contínuo. Revista Brasileira de Zootecnia, v. 28, n. 3, p. 459-467, 1999.

VAN SOEST, P. J. Nutritional ecology of the ruminant. 2. ed. New York: Cornell University, 1994.

Recebido em: 09/05/2007

Received in: 05/09/2007

Aprovado em: 31/07/2007

Approved in: 07/31/2007 